Supporting Information for

\title{
A Comparative Study on Luminescent Copolymers of Fluorene and Carbazole with Conjugated or $\delta$-Si Interrupted Structures: The Steric Effects
}

Xue-Ming Liu, ${ }^{1, *}$ Jianwei $\mathrm{Xu},{ }^{1}$ Xuehong $\mathrm{Lu}^{2}$ and Chaobin $\mathrm{He}^{1, *}$

${ }^{1}$ Institute of Materials Research and Engineering, 3 Research Link, Singapore 117602

${ }^{2}$ School of Materials Science and Engineering, Nanyang Technological University, Nanyang Avenue, Singapore 639798

\section{* Corresponding Authors}

Xue-Ming Liu (Dr.) and Chaobin He (Dr.)

Institute of Materials Research and Engineering, National University of Singapore, 3 Research

Link, Singapore 117602

Fax: 65-68727528

Email address: xm-liu@imre.a-star.edu.sg; cb-he@imre.a-star.edu.sg

Spectroscopic information for precursors 2 and 3, and polymers P1-P4 


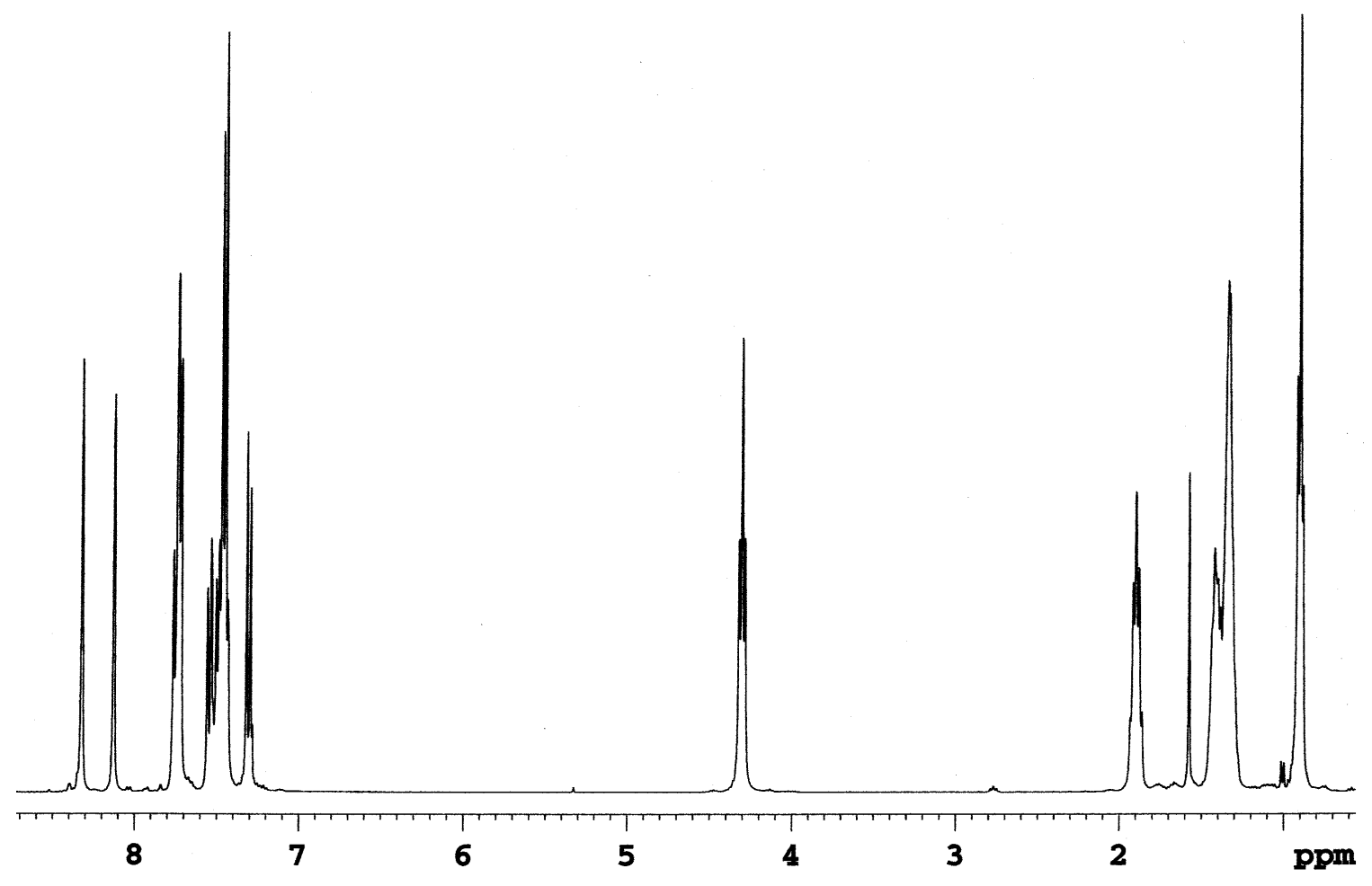

Figure S1. The ${ }^{1} \mathrm{H}$ NMR spectrum of $\mathbf{2}$ in $\mathrm{CDCl}_{3}$.

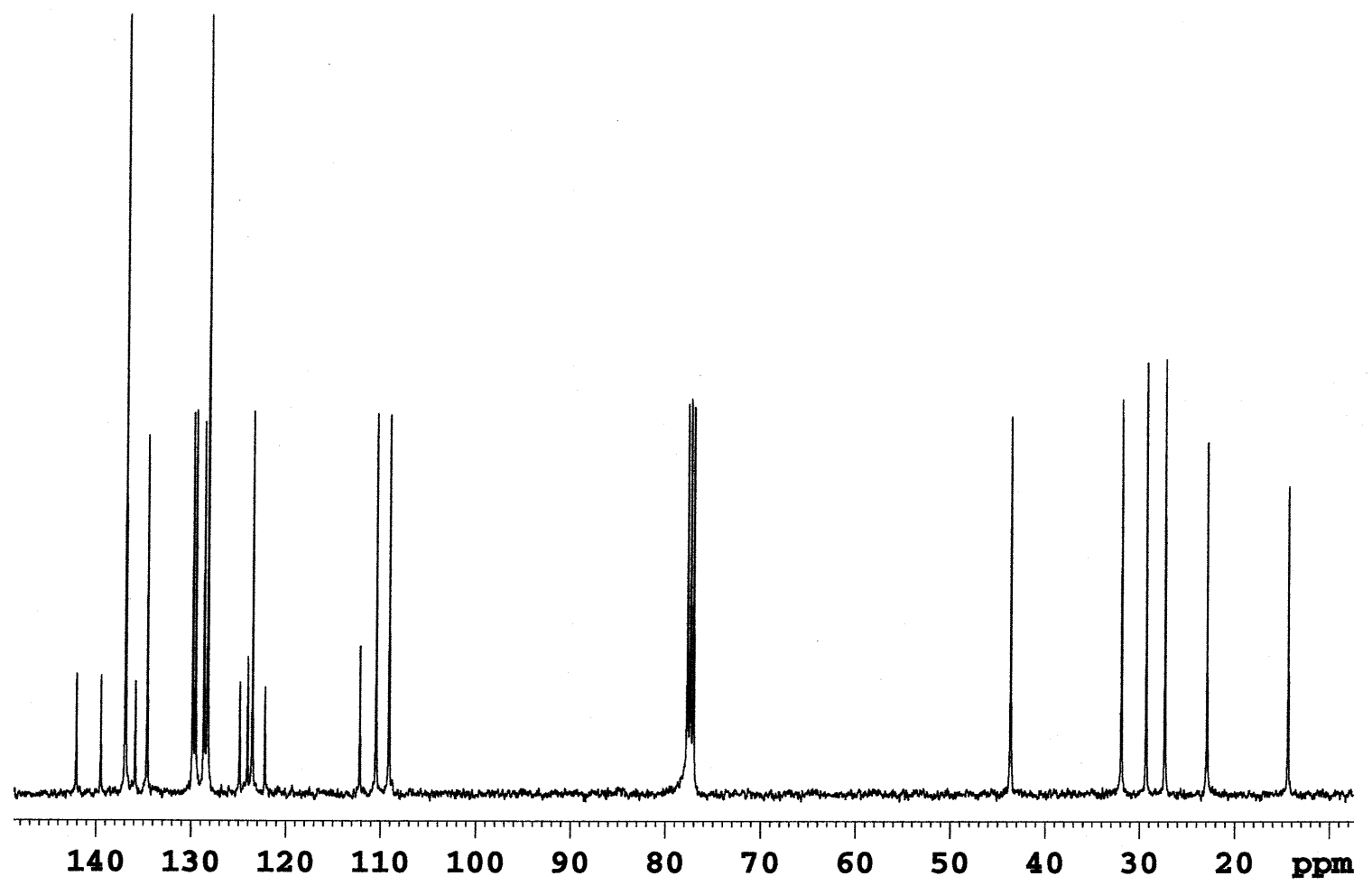

Figure S2. The ${ }^{13} \mathrm{C}$ NMR spectrum of $\mathbf{2}$ in $\mathrm{CDCl}_{3}$. 


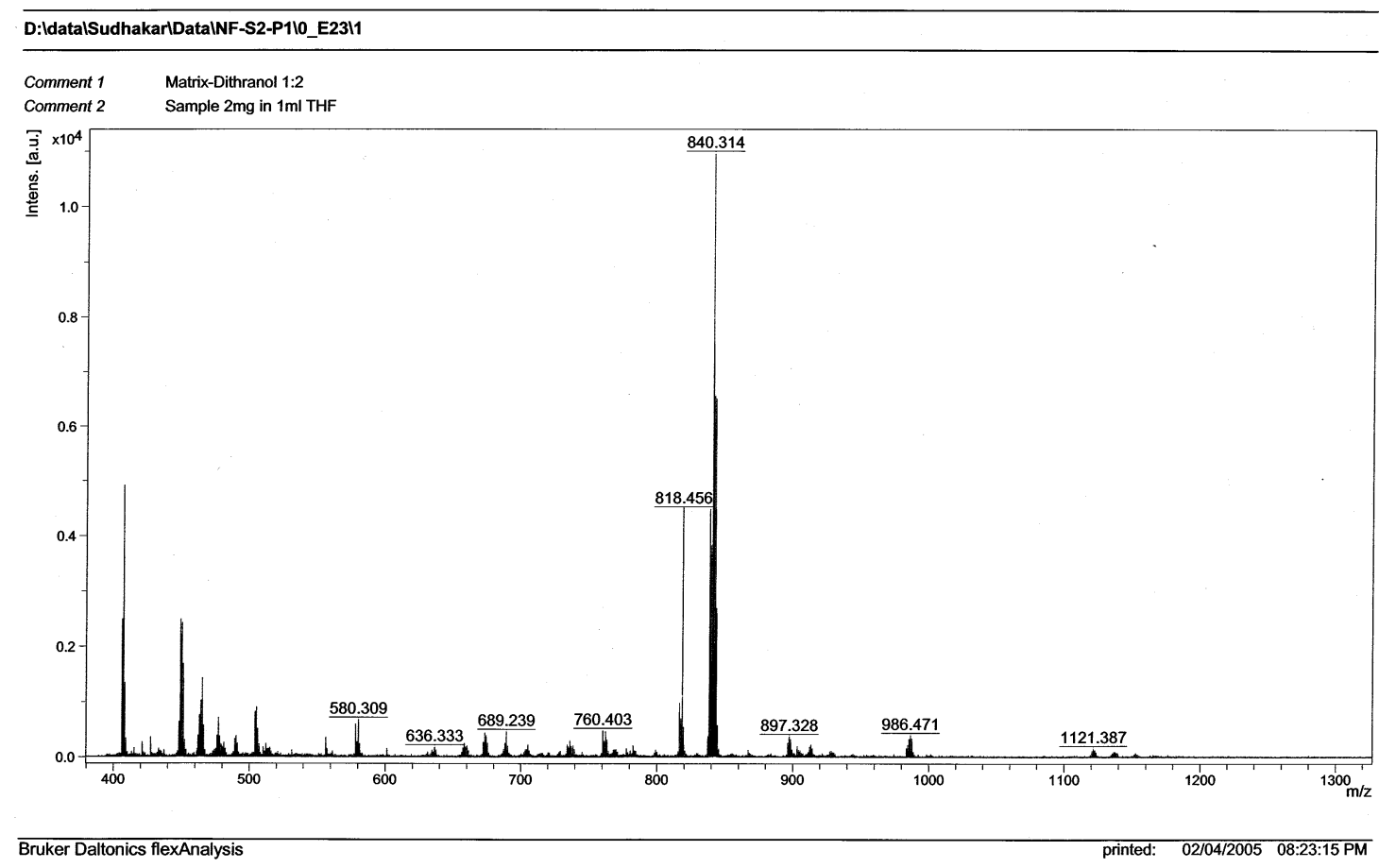

Figure S3. The MALDI-TOF MS spectrum of 2.

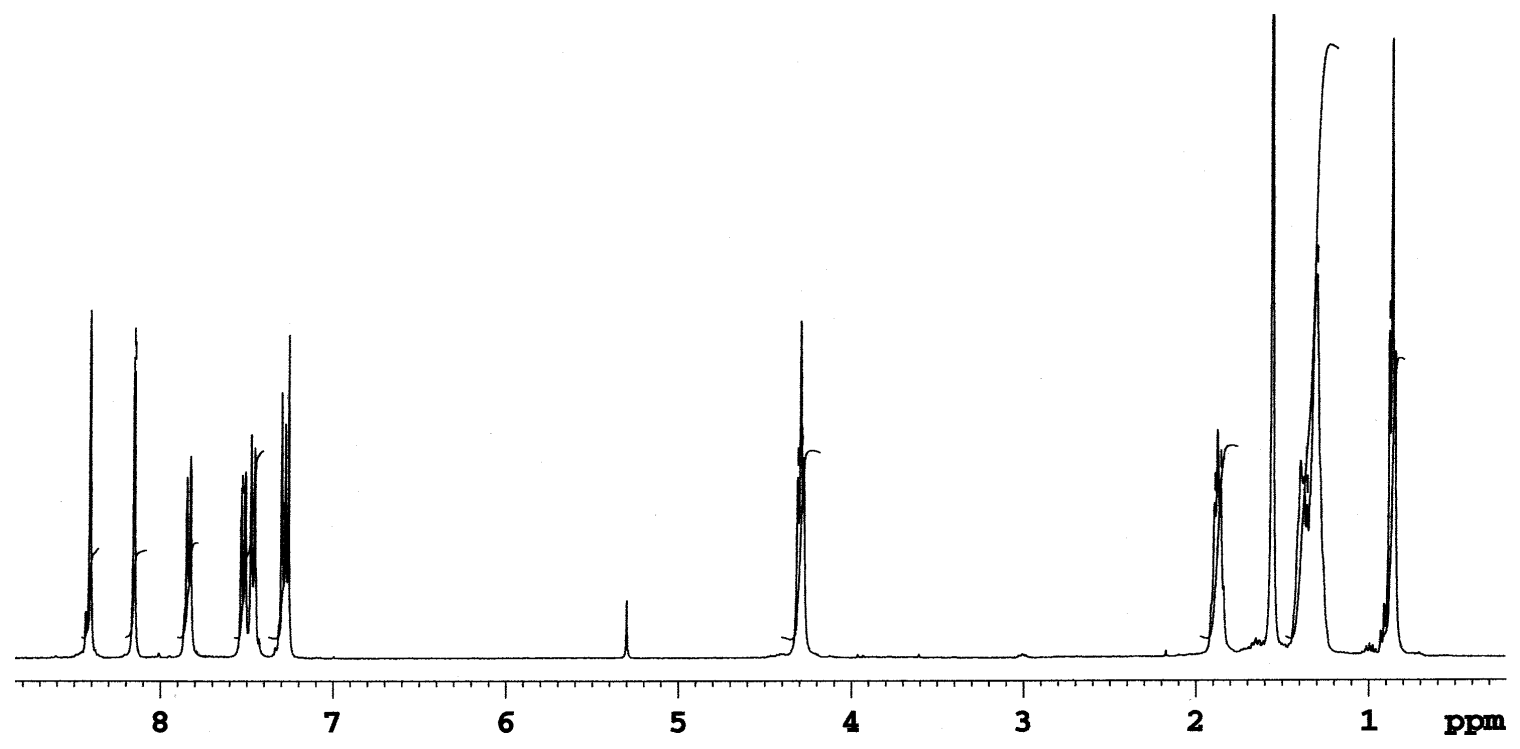

Figure S4. The ${ }^{1} \mathrm{H}$ NMR spectrum of $\mathbf{3}$ in $\mathrm{CDCl}_{3}$. 


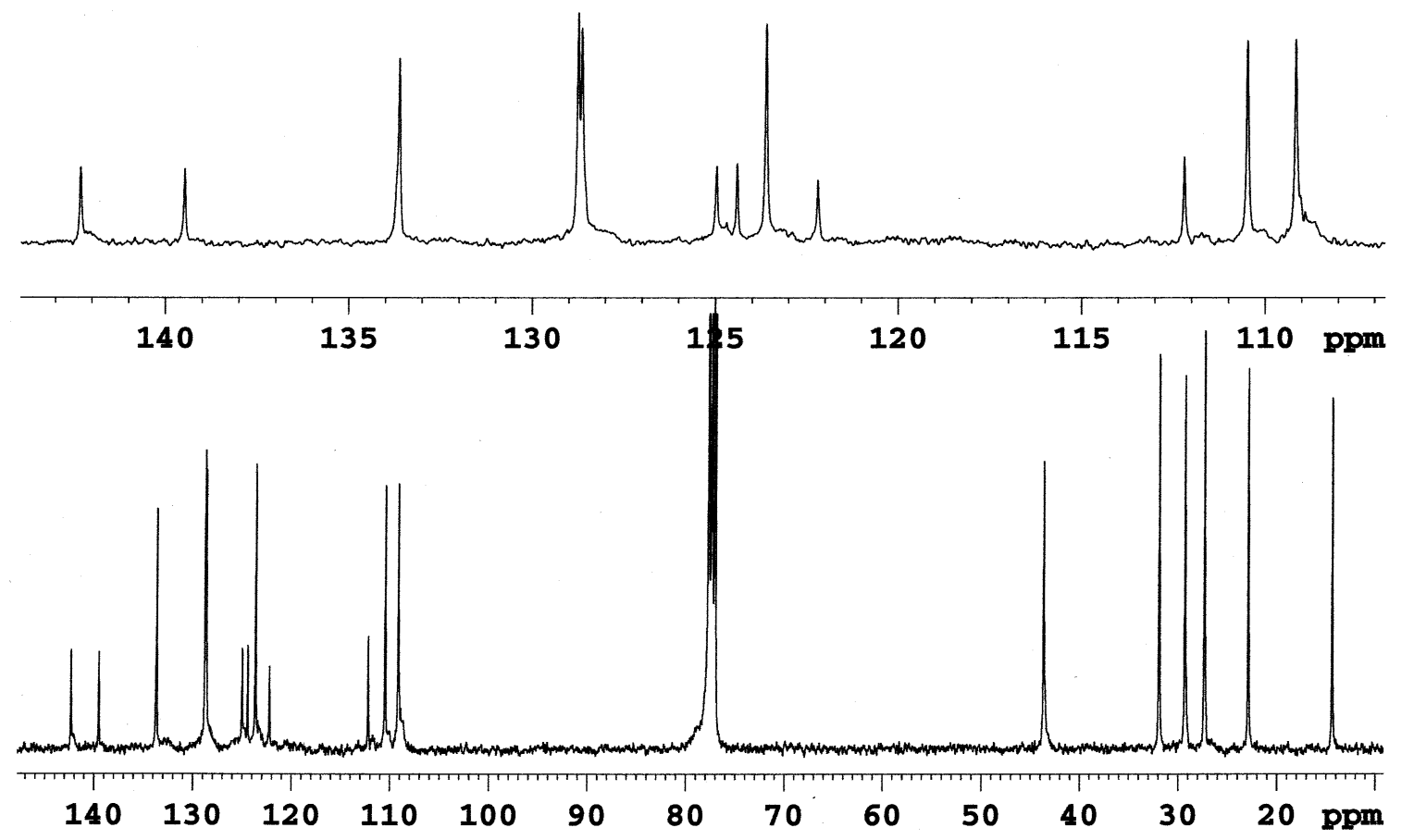

Figure S5. The ${ }^{13} \mathrm{C}$ NMR spectrum of 3 in $\mathrm{CDCl}_{3}$.

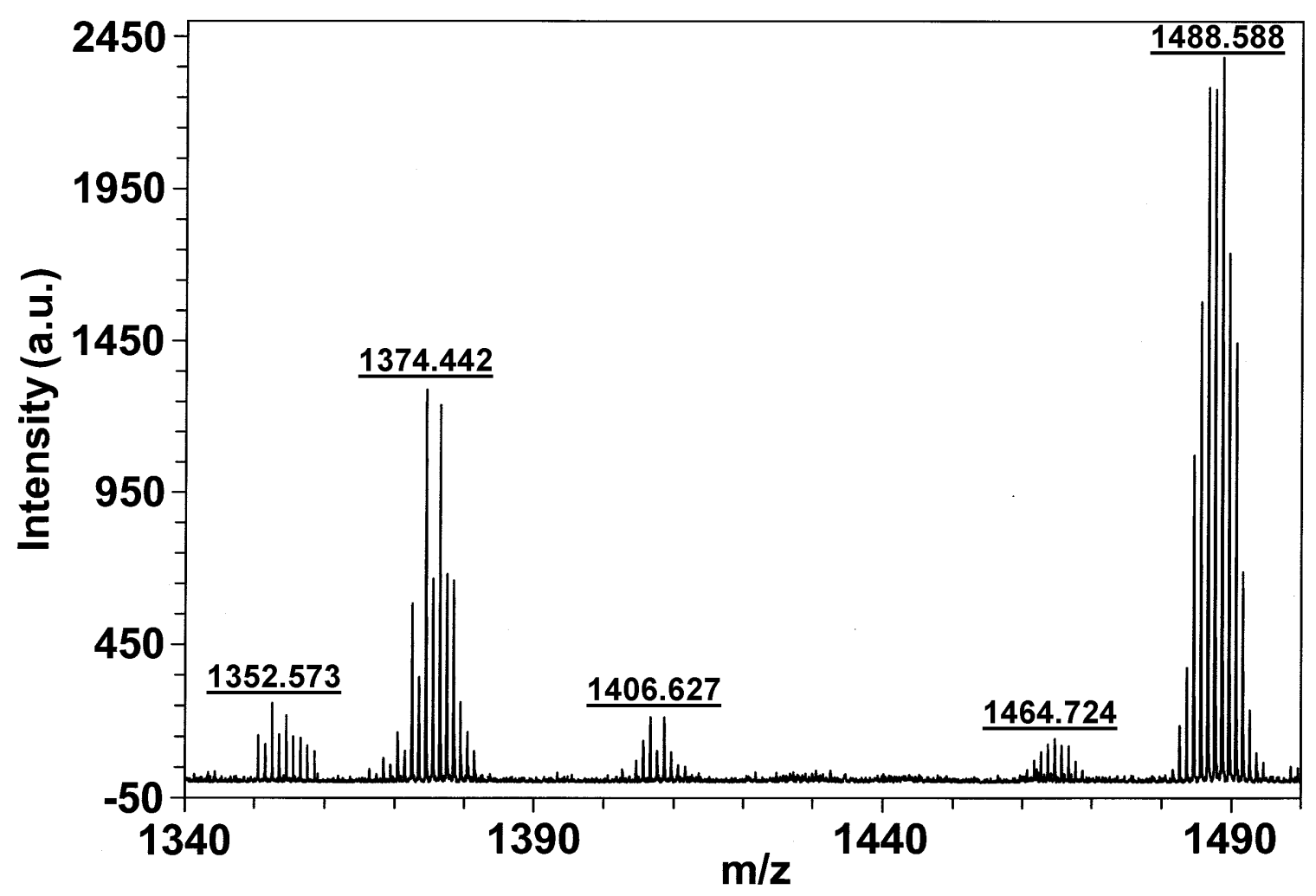

Figure S6. The MALDI-TOF MS spectrum of 3 


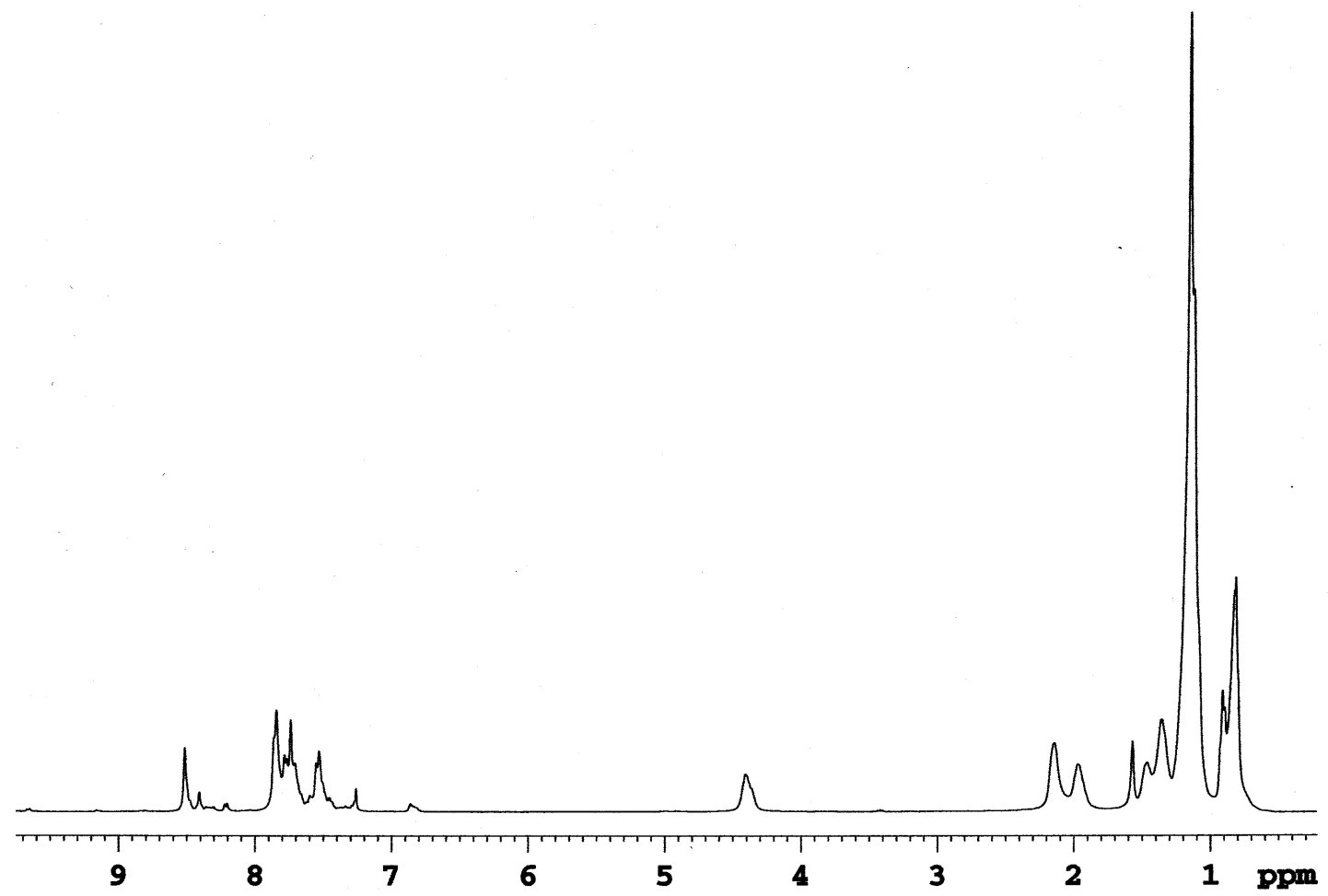

Figure S7. The ${ }^{1} \mathrm{H}$ NMR spectrum of $\mathbf{P 1}$ in $\mathrm{CDCl}_{3}$.
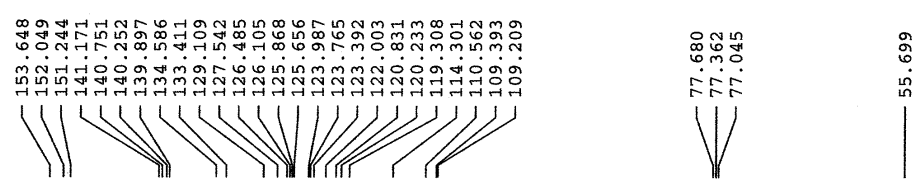

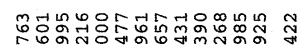

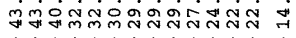

$11011 / 11 / 11$
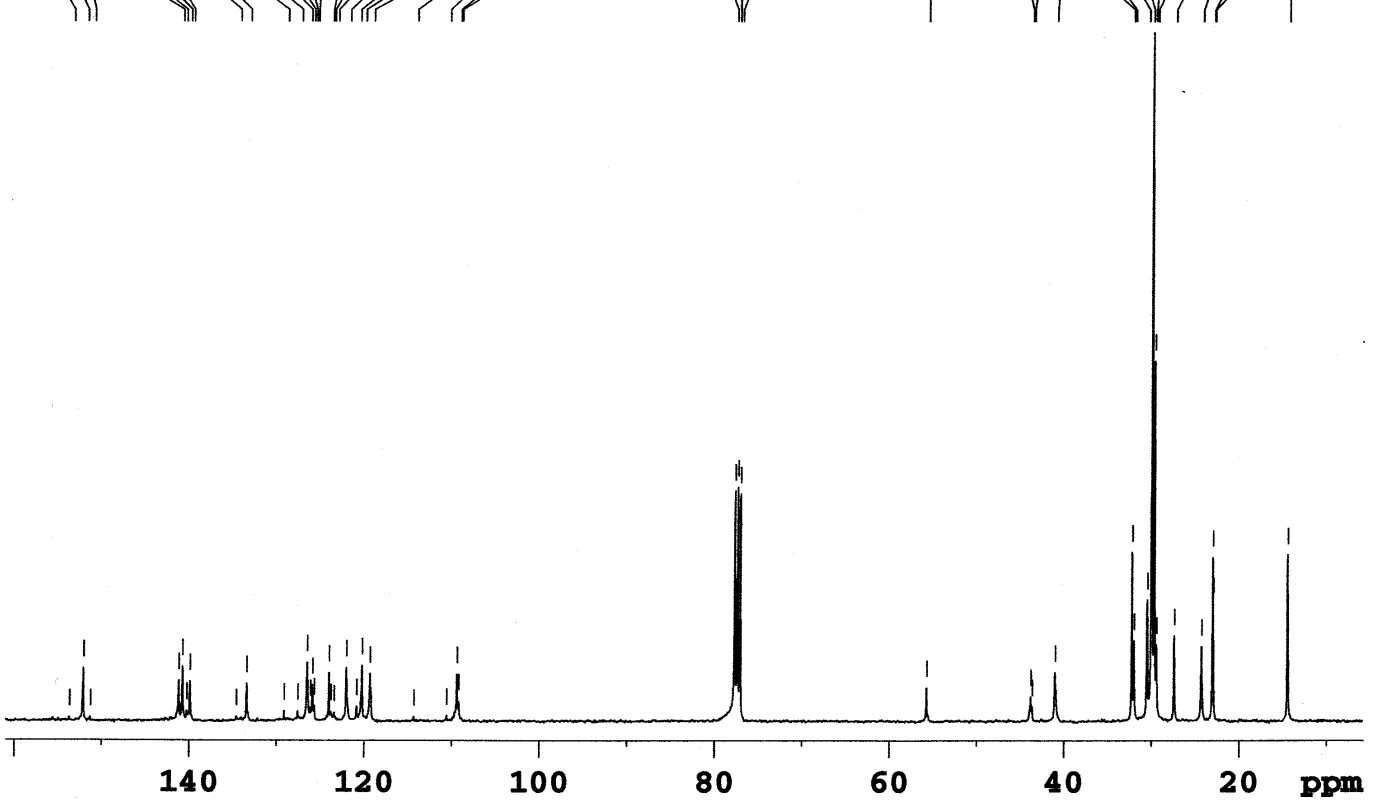

Figure S8. The ${ }^{13} \mathrm{C}$ NMR spectrum of $\mathbf{P 1}$ in $\mathrm{CDCl}_{3}$. 


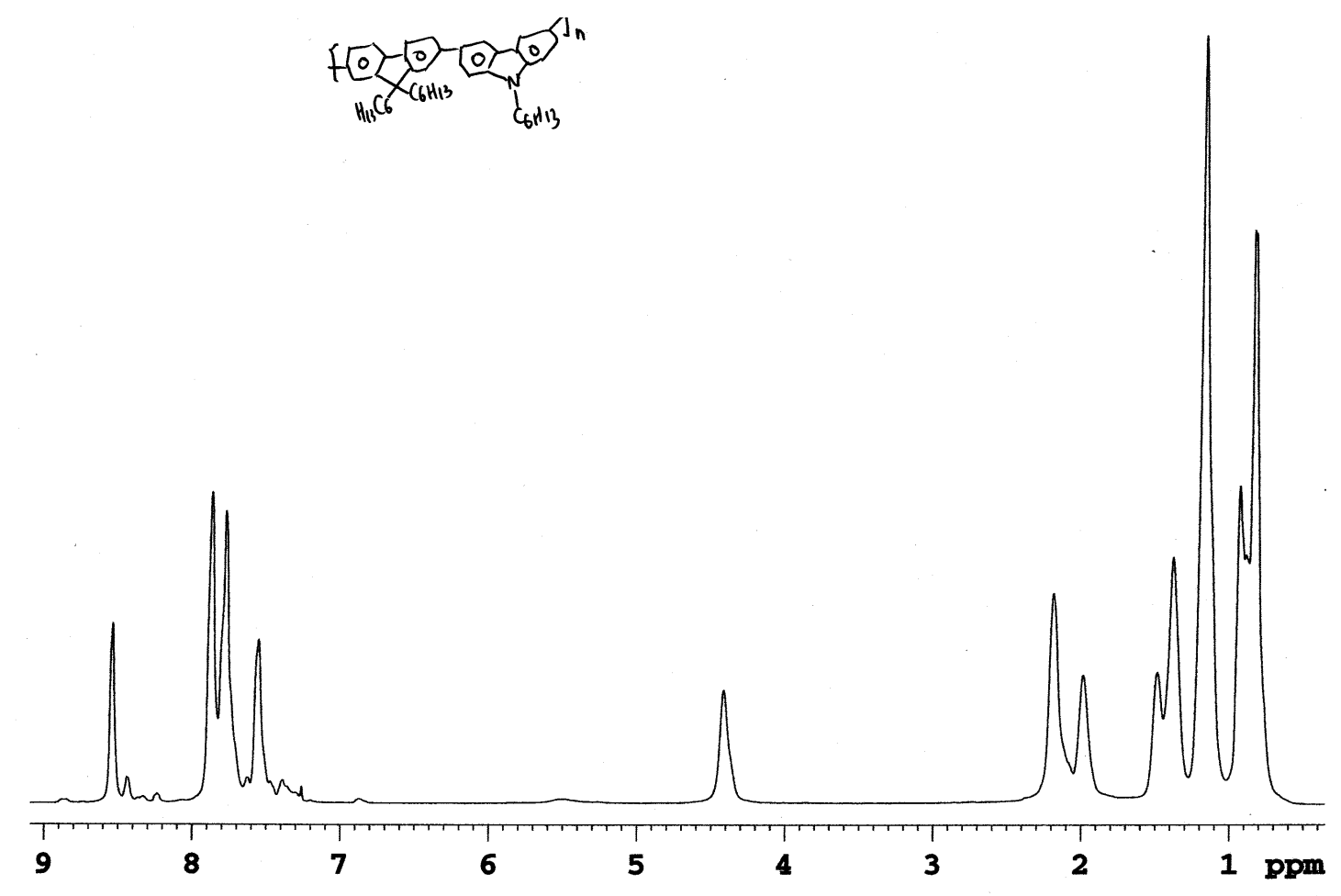

Figure S9. The ${ }^{1} \mathrm{H}$ NMR spectrum of $\mathbf{P 2}$ in $\mathrm{CDCl}_{3}$.

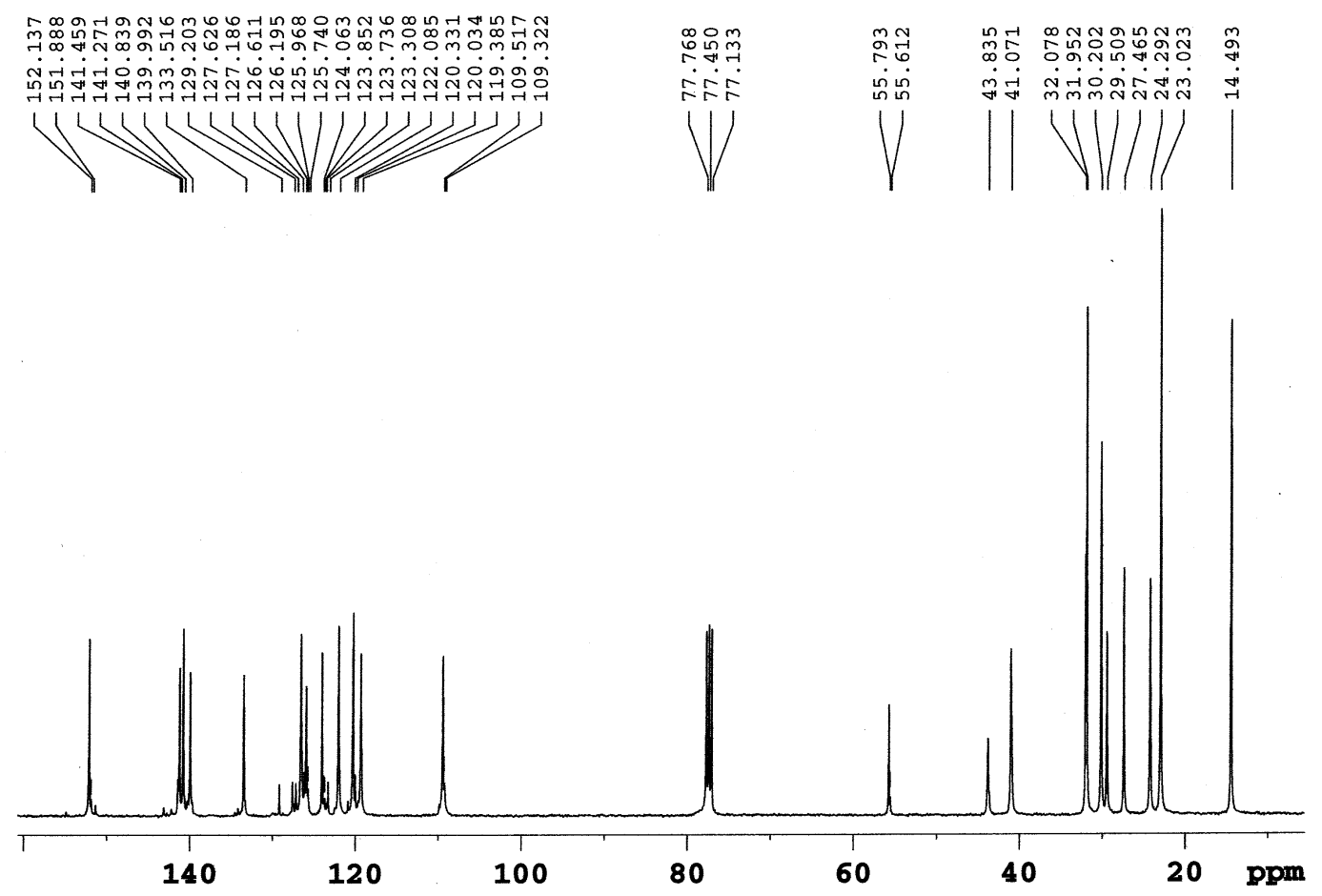

Figure S10. The ${ }^{13} \mathrm{C}$ NMR spectrum of $\mathbf{P 2}$ in $\mathrm{CDCl}_{3}$. 


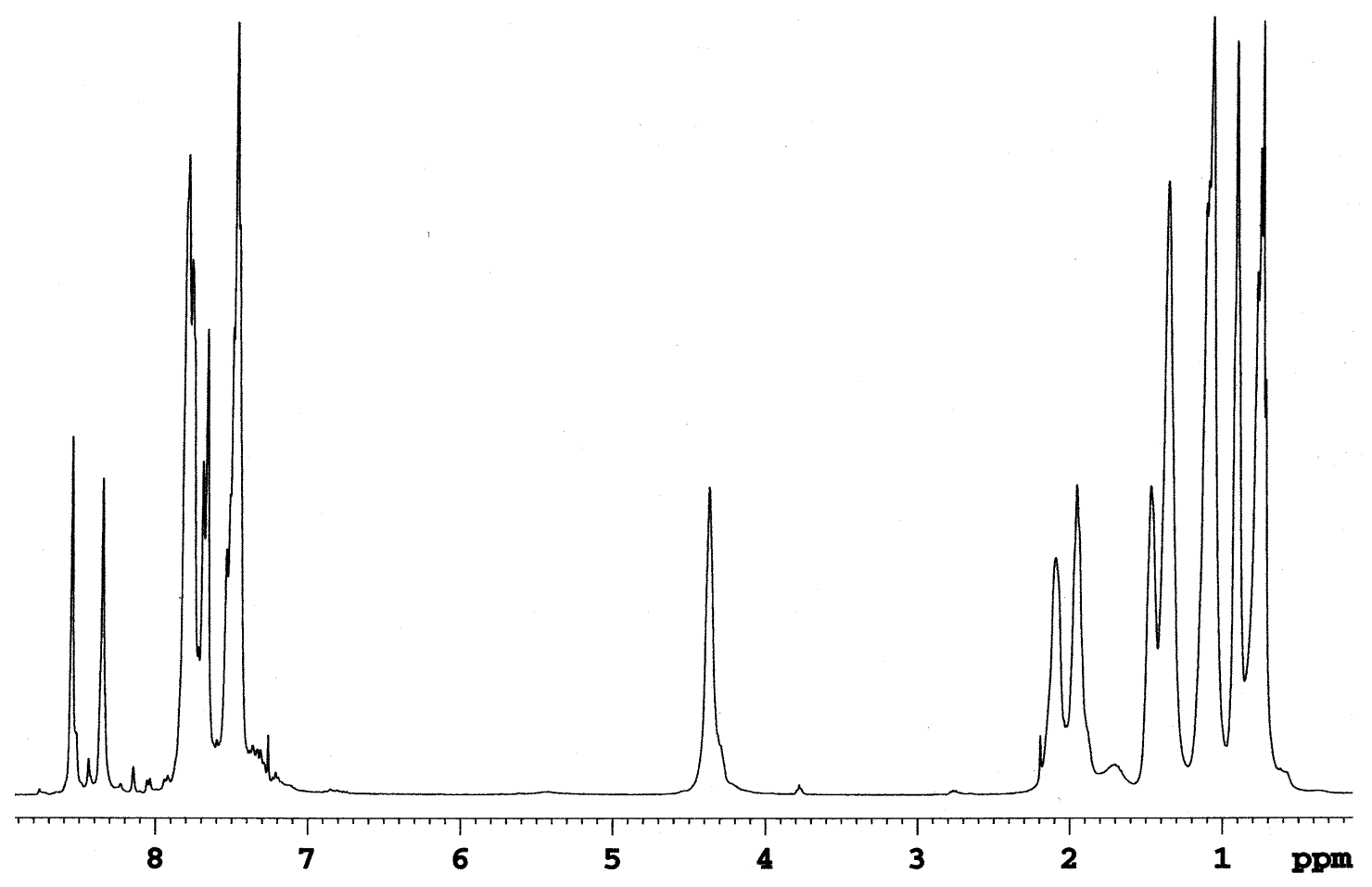

Figure S11. The ${ }^{1} \mathrm{H}$ NMR spectrum of $\mathbf{P 3}$ in $\mathrm{CDCl}_{3}$.

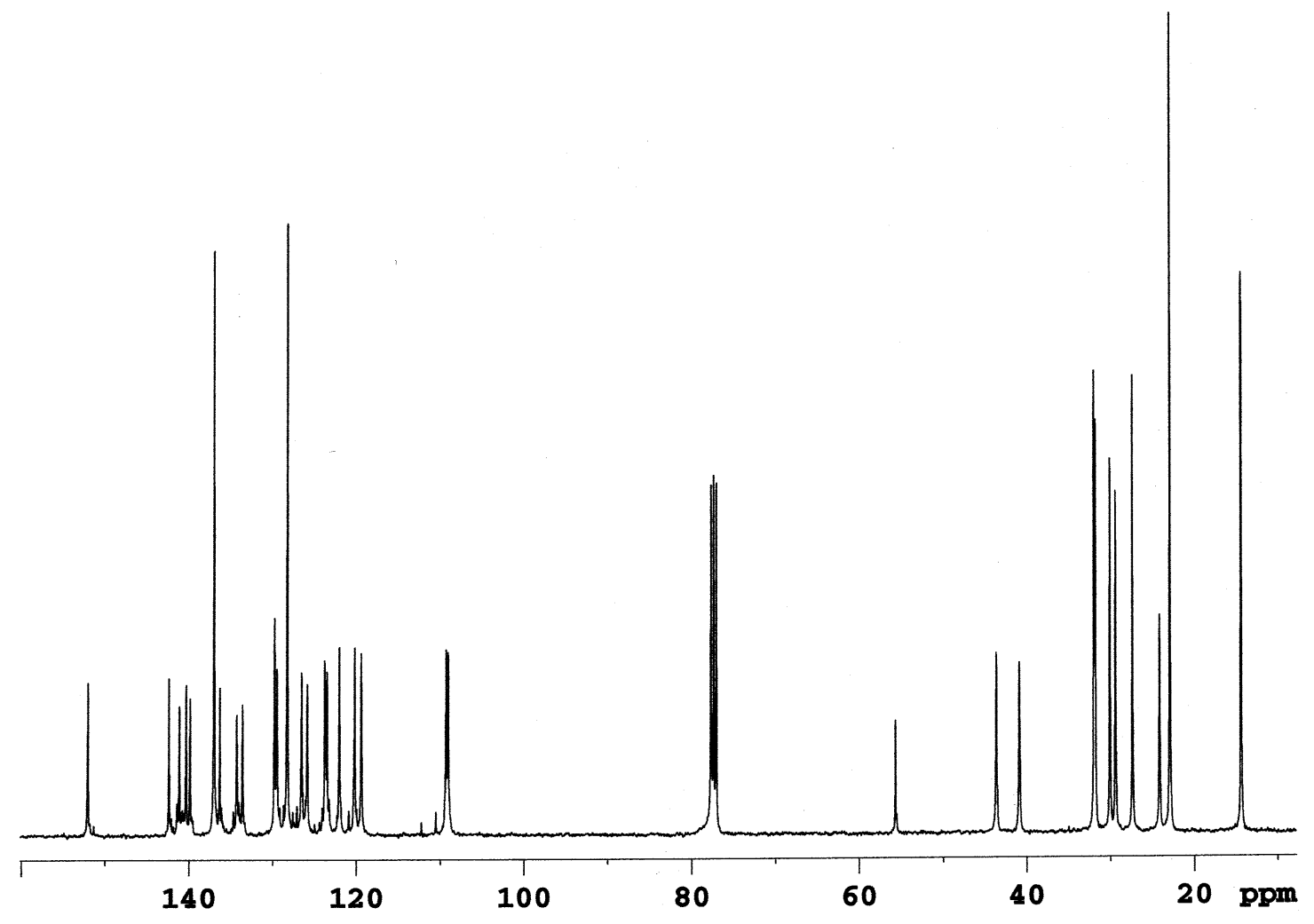

Figure S12. The ${ }^{13} \mathrm{C}$ NMR spectrum of $\mathbf{P 3}$ in $\mathrm{CDCl}_{3}$. 


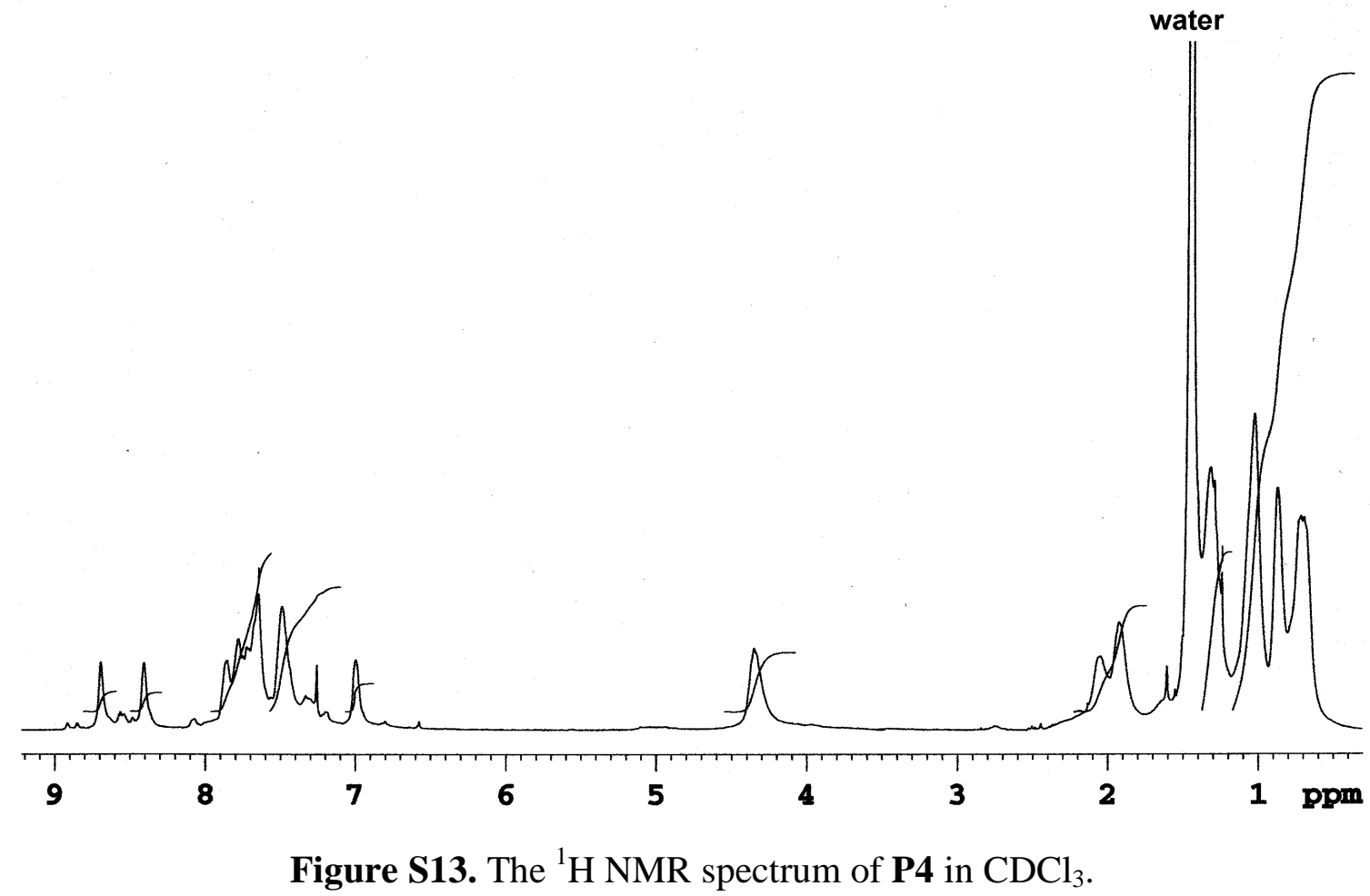

CBZ-C3-hexyl-fluorene-hyperbranched polymer CDCl3
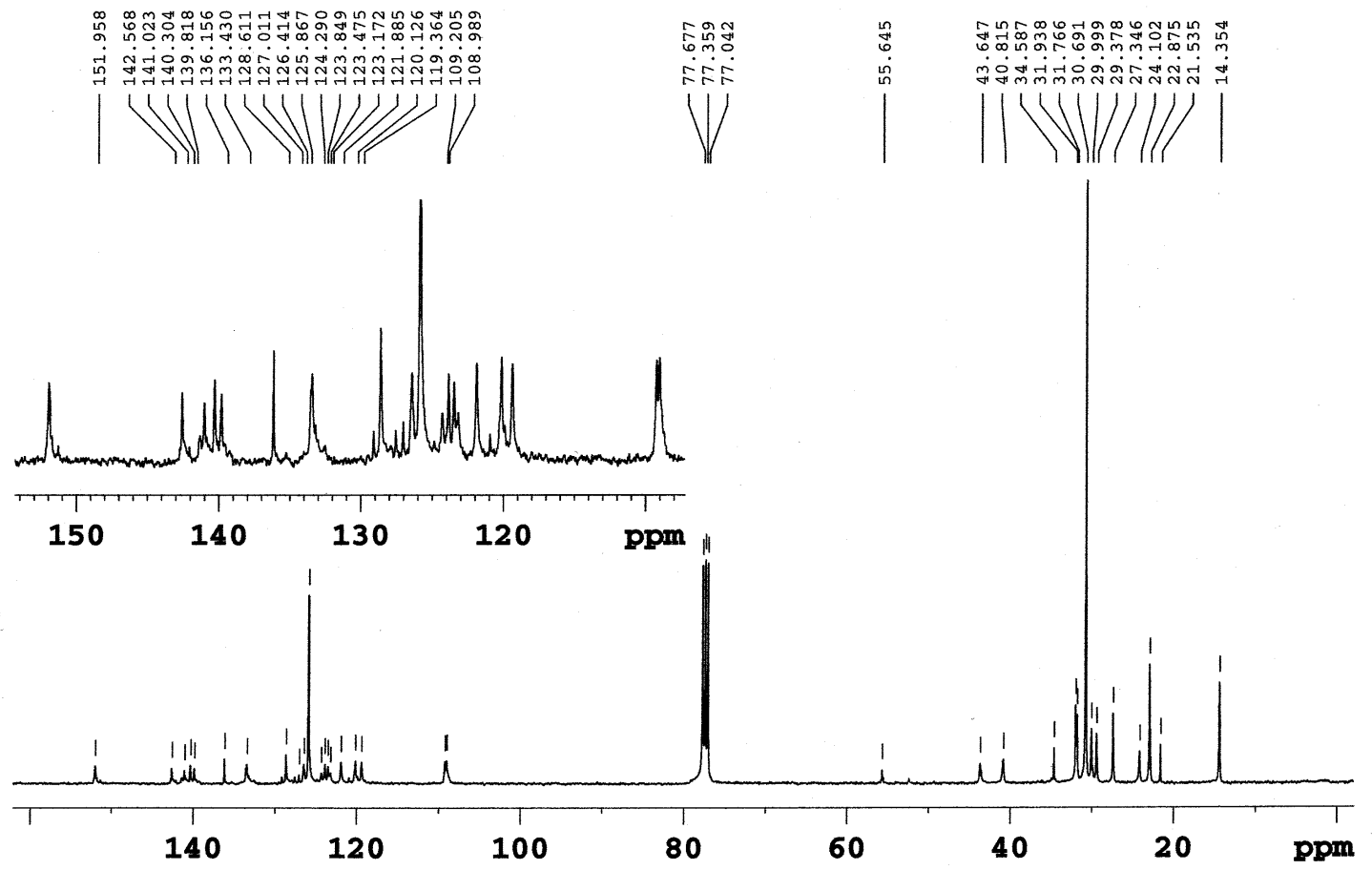

Figure S14. The ${ }^{13} \mathrm{C}$ NMR spectrum of $\mathbf{P 4}$ in $\mathrm{CDCl}_{3}$. 